\title{
'It was almost like the opposite of what I needed': A qualitative exploration of client experiences of unhelpful therapy
}

Christine Bowie Julia McLeod John McLeod

This is the peer reviewed version of the following article:

Bowie, C., McLeod, J. and McLeod, J. (2016), 'It was almost like the opposite of what I needed': a qualitative exploration of client experiences of unhelpful therapy. Counselling \& Psychotherapy Research, 16(2): pp.79-87.

It has been published in final form at DOI: https://dx.doi.org/10.1002/capr.12066

This article may be used for non-commercial purposes in accordance with Wiley Terms and Conditions for Self-Archiving 
Pre-publication copy of:

Bowie, C., McLeod, J., \& McLeod, J. (2016). 'It was almost like the opposite of what I needed': A qualitative exploration of client experiences of unhelpful therapy. Counselling and Psychotherapy Research, 16(2), 79-87. https://doi.org/10.1002/capr.12066

"It was almost like the opposite of what I needed": a qualitative exploration of client experiences of unhelpful therapy

Christine Bowie (1), Julia McLeod (1), John McLeod (2)

(1) Division of Mental Health Nursing and Counselling, University of Abertay

(2) Department of Psychology, University of Oslo 


\begin{abstract}
Background: The issue of unhelpful and harmful therapy outcome has received an increasing amount of attention within the research literature in recent years. However little research exists on the client's perspective of what constitutes unhelpful therapy. Aim: The aim of this study was to explore clients experiences of unhelpful therapy. Method: Semi-structured interviews were carried out with ten therapists, around their experience of having received unhelpful therapy. Interview transcripts were analysed using Interpretative Phenomenological Analysis.

Findings: Participants recounted therapy episodes characterised by an absence of negotiation, collaboration and care, pivotal moments when they knew that they would not return, and on-going negative effects.

Conclusions: The findings of this study have implications for training and strategies for supporting clients who have been harmed by therapy.
\end{abstract}

Keywords: client dissatisfaction, client perspective, counselling, ethics, qualitative, unhelpful experience 
Title: "It was almost like the opposite of what I needed": a qualitative exploration of client experiences of unhelpful therapy

The topic of harmful or negative outcomes of counselling and psychotherapy has long been acknowledged as an important issue for the profession (Bergin, 1963; Binder \& Strupp, 1997; Grunebaum, 1986). Some therapists record negative outcomes in more than half of the clients who consult them (Kraus et al., 2011; Okiishi et al., 2003). In general, therapists are not proficient in identifying lack of client progress (Hatfield, et al., 2010), and may fail to address treatment failure for many sessions, even when it has been recognised (Stewart \& Chambless, 2008). The question of to tackle such issues has been widely discussed (Castonguay et al., 2010; Dimidjian \& Hollon, 2010).

The development of an understanding of the factors that contribute to negative and unhelpful outcomes, requires the use of a range of methodological strategies. Large scale studies and randomised controlled trials can identify broad categories of unhelpful therapy (Lilienfeld, 2007). However, symptom deterioration at the end of therapy, typically used in large-n studies as an indicator of unhelpful therapy, may not always be attributable to the intervention that the client has received, but instead can result from life events such as job loss. It is important to supplement the findings of large-scale studies, with research that explores the helpfulness or harmfulness of therapy in any specific case by asking the client for their views about what took place.

Research into client perceptions and experiences of unhelpful therapy reveals a complex picture. From the point of view of the client, there appears to exist a continuum of therapy harmfulness. Some therapist interventions and attitudes may be experienced as temporarily harmful or hindering, in the sense of interrupting the flow 
of therapy (Paulson et al., 2001) but without resulting in lasting damage. A more significant level of harm has been observed in studies that have documented the experiences of clients who complete therapy, but remain dissatisfied and disappointed at the end of treatment because they believe that they would have done better if they had seen a different type of therapist (Nilsson, Svensson, Sandell, \& Clinton, 2007; von Below \& Werbart (2012). The harm in these instances can be understood in terms of wasted time or lost opportunity. A further degree of unhelpfulness is experienced by clients who terminate their therapy early, on the basis of negative experiences. These individuals suffer not only from wasted opportunity, but also from the stress involved in coping with traumatic or upsetting events. Finally, some clients report that therapy has been positively abusive and destructive (Bates, C. and Brodsky, 1989; Bates, Y., 2006). At this end of the harmfulness dimension can also be found evidence from official records, in respect of clients who make complaints to professional bodies (Khele, Symons \& Wheeler, 2008; Symons et al., 2011) on the basis of tangible harm that has been incurred.

It can be hard for clients to articulating their dissatisfaction to their therapist (Levitt, 2002; Sells et al., 1996). Instead, clients may take personal responsibility for difficulties experienced in therapy, blaming themselves rather than the "expert" therapist (Dale, Allen, \& Measor, 1998; Lietaer, 1992). The theme of destructive use of therapist power runs through many client accounts of experiences of having been harmed or damaged by therapy (Armsworth, 1990; Bates, 2006; Dale, Allen and Measor, 1998; Frenken \& van Stolk, 1990). In a study of clients who had reported that their therapy had not been helpful, von Bulow and Werbart (2012) found that dissatisfaction was associated with two main factors. These clients believed that the therapy approach to which they had been exposed, was not relevant to their needs. 
They also described their therapists as inattentive and non-responsive. Taken together, these clients described themselves as having been emotionally and relationally abandoned. It was also notable that, at the same time, these clients acknowledged the existence of positive aspects of the therapy that they had received.

\section{Method}

In order to develop a detailed understanding of what the experience of unhelpful therapy is like from the point of view of the client, a qualitative research approach was adopted, based on in-depth interviews with clients around a specific episode of unhelpful therapy.

\section{Design}

The study used Interpretative Phenomenological Analysis (IPA) (Smith, Flowers, \& Larkin, 2009), a qualitative methodology that has been widely applied in research into counselling and psychotherapy. The aim of IPA is to explore the lived experience of individuals by identifying themes that convey the essence of the topic being investigated.

\section{Participants}

The research was carried out with a purposive sample of 10 participants who had, by their own definition, an experience of receiving unhelpful therapy. Because it was anticipated that being interviewed about harmful therapy might be emotionally 
challenging, it was decided, for the purposes of this exploratory study, to recruit participants who were qualified therapists, and thus in a position to handle the demands of the interview task. Participants were invited to take part through the professional network associated with the counsellor training programme at the University of XX. The network comprised current and past staff and clinical supervisors, and former students associated with the programme, as well as individuals who had attended Continuing Professional Development workshops at the university. Information about the study was sent by email to 30 potential participants. To ensure participant capacity to deal with the emotional demands of the interview, students currently in counsellor training were not included. Inclusion in the study was on the basis of self-identification as having received unhelpful or harmful therapy. A sample of one male and nine female participants was recruited, with ages ranging from thirty to sixty-two years. All of the participants were experienced practitioners, who identified themselves as counsellors (8) or psychotherapists (2). Two of the participants described unhelpful experiences that had occurred during their first engagement with therapy, prior to entering training: six episodes occurred during the period of therapy training ( 5 of these episodes took place in the context of personal therapy required by the training institution), and two described episodes that happened post-training. The episodes of unhelpful therapy disclosed in the study took place between twelve years and one year before the date of the interview. Not all participants were able to identify the model of therapy being used by the unhelpful therapist that they had consulted. The therapy orientations that were described included psychodynamic, person-centred, bodywork, and integrative. Two of the unhelpful therapists were seen in university student counselling settings, two in workplace schemes, while the remaining 6 were in private practice. None of the 
unhelpful therapies took place in NHS or voluntary sector settings. The first 10 individuals to contact the researcher were recruited into the study. The sample size was determined in advance of data collection, in accordance with IPA guidelines (Smith et al., 2009). Offers to be involved were received from many more potential participants. In later sections of the paper, participants are indicated by $\mathrm{P} 1, \mathrm{P} 2$, etc.

\section{Ethical procedures}

The principal researcher emailed an invitation with information about the study and a consent form. The researcher emailed all participants post-interview to elicit feedback, check that they were unharmed by taking part in the research and thank them for their participation. Ethical approval for the study was obtained from the XXXX Research Ethics Committee, University of YYY.

\section{Interviews}

Semi-structured, face-to-face interviews were conducted by the principal researcher. Interviews were audio recorded, lasted approximately 50-90 minutes and were carried out in offices at the University of YYY and other appropriate professional settings (but not in the home of the participant). Interviewees were invited to talk about their experience of a single treatment episode (defined as the whole of their contact with one therapist) that they assessed as having been personally unhelpful or harmful. The interview schedule invited participants to explore the following topics: How did you access counselling and how long ago was it? How did you recognise dissatisfaction with counselling? What did you do when you realised that the therapy was unhelpful? 
What was the impact of unhelpful counselling on your life? Interviewees were encouraged to move away from the scheduled questions and elaborate on their experience of being a client recipient of harmful therapy. A copy of the interview schedule was provided in advance

\section{Analysis}

The researcher subjected the transcripts to qualitative analysis, using the method of Interpretative Phenomenological Analysis (IPA) (Smith et al., 2009). Initial coding was used to identity emergent subordinate and superordinate themes. The final two interviews were used to check for new or emerging themes. In accordance with principles of good practice in qualitative inquiry (Elliott, Fischer, \& Rennie, 1999) independent auditing of the analysis was provided by two experienced qualitative researchers, and members of a research peer group.

\section{Researcher reflexivity}

For the principal researcher, an interest in the topic of harmful therapy arose during training, and was associated with the personal discovery that not all therapy is helpful. In order to monitor and learn from her personal experience of carrying out the study, the researcher kept a research journal, which was discussed during supervision. The co-authors were academic supervisors of the principal researcher, with many years of experience as therapists, trainers and researchers. As practitioners, all three members of the team espoused a pluralistic approach to therapy, that emphasised the importance of a collaborative way of working based on client feedback, and believed 
that harmful therapy could often be attributable to an absence of authentic

collaboration. Members of the team also held the view, based on personal experience, that the personal style and attitudes of some therapists produced negative outcomes in a substantial proportion of their clients.

\section{Results}

Four superordinate themes emerged from IPA analysis of the transcripts: sourcing $a$ therapist; the therapist working to their own agenda; the pivotal moment-deciding not to continue; the impact of receiving unhelpful therapy. Subordinate themes, reflecting the rich texture of meaning within each of these main themes, are listed in Table 1.

[insert Table 1 about here]

Sourcing a therapist

Participants entered therapy in varying ways. Two participants accessed free therapy through student services at the University where they were studying. Both were randomly allocated to a therapist. A further two participants made use of counselling services organised through their employer. The remaining six participants entered into private/paid counselling through varying selection methods. For example, P2 sought the advice of a friend who had previously benefitted from therapy whilst P4 followed the recommendation of her counselling supervisor who she trusted. The remaining four participants searched agency advertisements and the Internet, checking reviews 
and qualifications in a search for a potential therapist who would meet their personal needs. Each of the participants in the study described the therapists that they saw as well-qualified, with good reputations or working in agencies that had good reputations. In the interviews, it seemed important for participants to emphasise that they had positive expectations at the outset of therapy, based on "due diligence" in the choice of therapist.

The therapist working to their own agenda

A central aspect of the experience of unhelpful therapy, for all participants, was the sense that their therapist was following his or her own agenda, and not responsive to what the client needed or wanted.

This is how it is going to be

All participants reported that the work focused on the things that the therapist thought were important. The therapist seen by P4 explicitly stated at the outset that "this is how it is going to be". P8 recounted that she went into therapy looking for support in dealing with "the here and now" of the terminal illness of her spouse, to be confronted by a therapist who insisted that her distress must be rooted in childhood experience:

I was living my life in the moment and I was trying not to think too far ahead........because it was disasters coming ...over and over again ...nights and nights of not sleeping.........so my life was pretty hell.......... and so for him to go we're going to deal with this from digging in your past..............didn't 
make any sense. he had a way of dealing with things and that's the way he was going to do it whether that was going to work for me or not.....(P8)

For others, it took a number of sessions to get to the point where they realised that the therapist was taking them in their own preferred direction:

I felt like I was some kind of experiment...it felt like I was being prodded and probed and not actually.....it was all for his benefit .....that's what I got a sense of ...actually, you know he got more out of our sessions than I got out of the sessions....(P3)

A similar meaning was conveyed by three participants who expressed a sense that the therapist was working for their own financial benefit rather than addressing the needs of the client.

You are not important to me: an absence of genuine interest and caring

All participants described themselves as being vulnerable when entering therapy and looking for the therapist to "care for me" (P9). However, they described feeling no connection or warmth from the therapist in response to their distress. Participants reported that they had been looking for some sort of acknowledgment and validation of the emotions that they were sharing, but that they were not being "met" by their therapist. For some there was a sense of arrogance and "an air of superiority" (P5) from the therapist, which increased their sense of not being valued: 
I didn't get a sense of empathy from him, I didn't get a sense of it...he was, he was, I got a sense of... there was a sense of arrogance to him. and it .....I don't know if I got a sense of this or if it's what he said to me in the last session but I got a sense that it wasn't actually about me, it was about him...(P3)

None of the research participants recalled their therapist ever checking-in or having any form of discussion about what they wanted from therapy or if therapy was indeed helping. Faced by these unhelpful experiences, most participants adopted a strategy of hoping it would get better.

The pivotal moment: deciding not to continue

All of the participants in the study described a specific moment during a session, when they realized that the therapy was not helping, and decided not to continue. For some this was in the first session, while for others it was after they had attended a number of sessions.

Two participants used the term "shell shocked" to describe the point when they realised that they knew that therapy was not helping. P3 experienced herself as being "used" by her therapist to further his own learning:

...he was thanking me for coming......[because] he found me so interesting and he was going to read further [about my problem] (P3) 
P5 described feeling very vulnerable when her therapist engaged in inappropriate self-disclosure:

...way over the top and very inappropriate... I think that I went into a bit of shock ...I thought ... I don't trust him anymore in fact I feel really uncomfortable with him ... I felt quite afraid of him at that point ...I mean I grabbed a pillow and kind of had it like a barrier in front of me... (P5)

In contrast P6 had felt that therapy was working until her therapist broke her confidentiality. She was willing to forgive him. However when she challenged him about what had happened, his response undermined all the work that had gone before:

I felt really small. I had challenged him and he had made me feel really small. It was almost that I should feel guilty for being annoyed at him and that my feeling weren't important. It was a complete lack of ownership on his part that got me.

In the interviews, these pivotal moments were vividly remembered and recounted in detail and with feeling. They seemed to represent an essential experience of not mattering, or being ignored or pushed aside, at a moment of vulnerability when the client expected and wished for the acceptance and understanding of their therapist. These moments could be regarded as pivotal in the sense that there was a fundamental shift in the balance of the client's attitude toward their therapist. Up to that point, the client had given their therapist the benefit of the doubt, blamed themselves for any shortcomings in the therapy, and 
hoped that things would get better. Following the pivotal moment, the client's faith and trust in the therapist were irretrievably destroyed.

Within the sample of participants in this study, five did not return to see their therapist following the session during which the pivotal moment occurred. However, the other participants in the study did return, for between one and ten further sessions.

The impact of receiving unhelpful therapy

All of the participants in the study reported that their experience of unhelpful therapy had a medium-term negative impact on their well-being. None of those who were interviewed described severe negative effect, such as suicidal thoughts or attempts, self-harm, breakdown or hospitalisation, or long-term harm.

\section{It left a bad taste}

There was a real sense that all participants felt let down/disappointed and sad about receiving unhelpful therapy. Some of them described being left with a "bad taste" (P2, P9) at the end of the experience. Others talked about previous therapeutic work being devalued or regretting sharing personal information that could not be taken back, in a sense leaving something of themselves in the room: 
I was really sad that I was potentially going to have to put a lot of good work aside that I wasn't really sure about the value of that anymore...you know once it had been spoiled because it was that kind of feeling (P6)

\section{Visceral hangover}

All participants in the study re-experienced the effect of the unhelpful therapy during the interview process:

I still experience that......I go back to that chair and I can remember the almost blue ice cold in the room .....(P7)

.I can feel the anger ....... I remember when I left.........I was so relieved that I would never have to see that man again.....I remember feeling really angry..........it felt invasive (P3)

For a few there was a sense that they had still not fully recovered from the experience, and were now reluctant to trust or open up so freely in the future.

\section{Feeling cheated}

In his interview, P9 summed up a sense of being cheated that was implicit in many client stories: 
....the word 'con' - that sort of captures some of it. It's like a confidence trick, if you think about criminals and confidence tricksters, they kind of make you think that your getting a good deal....they hook you in.... and you suddenly realise that you've been cheated. (P9)

I left something of myself in the counselling room

Participants voiced regret at having shared that "precious" (P10) element of themselves with the therapist, which was for many something that they had never done before and real sense of sadness that they could not take the sharing back: "I felt like I had something stolen from me" (P9); "it's almost like, that she kept that bit of me...."(P4).

The experience of complaining

Complaining about therapy presented great difficulty for the majority of participants, because of uncertainty over whether this was a "reasonable thing to do" (P1) or having "no energy to fight another battle" (P8). Only a few participants managed to complain to their actual therapist. P5 was the only participant who manage to make an official complaint, which proved to be a long and difficult process and required a great deal of resolve:

....had I been an normal member of the public I wouldn't have done it...I don't think I would have been able to handle it....it was just horrible ...the trauma the way the complaint was handled compounded the whole trauma. (P5) 
Long-term learning

All of the participants in the study believed that their experience of unhelpful therapy had provided some form of learning, albeit difficult and unpleasant at the time. In addition, all of them described ways in which their experience had informed their own work as therapists:

....even if I can't change things for people I will at least be honest and recognise their worries and talk to them, acknowledge their feelings and struggle .... as one human to another (P2).

\section{Discussion}

Clients in the study attributed the cause of their negative therapy to a failure on the part of their therapist to engage with them in an authentic and caring manner, work collaboratively, elicit feedback, or facilitate progress reviews. These findings have important implications for therapist training and supervision, and the management of counselling and psychotherapy services.

The findings of this study need to be interpreted with caution. For ethical reasons, participation in the study was limited to those who had completed psychotherapeutic training. As a consequence, participants in the study shared a generally benign attitude toward therapy, could draw on other helpful experiences of personal therapy, and had a vehicle through which to make positive use of what had happened. It seems likely that interviews with clients who had no involvement in the 
therapy professions, would be likely to reveal at least some examples of more severe negative long-term impact of bad therapy. Further limitations of the study included a lack of gender balance and absence of participants from under-served client populations, such as disabled or ethnic minority groups. Nevertheless, the individuals who did take part in the study were willing to talk honestly and at length about their experiences.

A similar pattern emerged in the narratives of all of those who were interviewed about their experience of unhelpful therapy. Participants believed that they had made a good faith choice of a therapist who was well qualified and whom they had every right to believe was competent. The majority of participants reported that although there were warning signals that their therapy was not proceeding in a particularly productive manner, they remained in therapy for some time in the hope that things would improve. Eventually, the therapist did something that was received as a fundamental personal rejection of the client as a person. Clients who had experienced harmful therapy found it hard to complain, and believed that this therapy episode had left them emotionally injured, which delayed their capacity to deal with the issues that had led them to seek therapy in the first place. Participants attributed their negative experience of therapy to the failure of their therapist to engage collaboratively with them at a personal level. Instead, their therapists were described as uncaring, arrogant, and following their own agenda.

In terms of making sense of these findings, an immediate question that arises is the extent to which bad therapy is unethical therapy. Several clients in the present study experienced explicit unethical practice, including receiving misleading information from their therapist with regard to contracting and finance settlement. The ethical issues uncovered in the present study were consistent with findings from 
research into the BACP complaints procedure (Khele, Symons and Wheeler, 2008). However, only one of the participants in the study defined her experience as an ethical breach, and sought ethical redress through a professional body.

The present study indicates that unhelpful therapy is associated with breakdown in the therapeutic relationship. Participants had demonstrated their vulnerability as clients, putting considerable trust in the knowledgeable, expert therapist, thereby putting considerable power in the hands of their therapist. It would appear that they held an implicit assumption that their therapist was a caring professional and would therefore endeavour to assist them. Experiencing their therapist as non-caring, and exploitative, was central to the harmfulness of therapy participants in this study. As reported by Dale, Allen and Measor (1998), clients were on the whole unable to communicate their dissatisfaction, and were remarkably tolerant of their therapist's failings (Paulson, Everall, \& Stuart, 2000). The fact that the majority of clients in the present study remained in therapy for some time following the "pivotal moment", provides a client-focused parallel to the findings of Stewart \& Chambless (2008) regarding therapist delay in acting on the realisation that therapy had lost its way. All participants of this study described in varying ways, feeling uncared for, "cheated" and "conned" by their therapist, who they perceived as false and offering a kind of "pseudo-caring". They left therapy feeling let down and disappointed. There was a sense of loss at having shared intimate personal details with their therapist, and then realising that they could not undo that sharing. Although based in a rather different sample, these themes are similar to those the sense of emotional "abandonment" that emerged in the von Below \& Werbart (2012) study of dissatisfaction in clients receiving long-term psychoanalytic psychotherapy in the context of the state-funded healthcare system in Sweden. These similarities suggest 
that both studies have identified a distinctive pattern of therapeutic failure that may occur in a regular basis. It would be valuable if future research could identify other trajectories of failed therapy and investigate the relative prevalence of each pattern in different therapy settings and client groups. The present study adds to the conclusions of von Below \& Werbart (2012) in observing that clients were aware of "pivotal moments" when they realize that the therapy they were receiving was unhelpful for them.

Participants of this study found it difficult to complain about therapy either directly to their therapist or through official channels. This is consistent with other research findings (Symons, 2012) attributing client failure to complain to a range of factors, such as lack of knowledge of how to complain, not sure whether it is a reasonable thing to do, not having the energy to take it further, or taking personal blame for therapy not working.

One of the key practical implications of research into negative experiences of therapy, is concerned with the provision of information and support for dissatisfied clients about how and when to complain, and training for therapists around prevention of negative outcomes. It was striking that all of the clients in this study recognised at the time, that the therapy they were receiving was not satisfactory. No participants described situations in which they realised after the end of therapy that their treatment had been less than unhelpful for them. Although it seems likely that further research would generate other examples of patterns of post-termination recognition of harm, the results of the present study strongly suggest that it would be valuable for client information to include the recommendation that they should be willing to trust their own personal judgement, if they have a sense that their therapy is not proceeding well. The finding that clients in the present study reported long-term learning as a 
result of acknowledging the inadequacy of the therapy they had received, may provide a perspective that could also be incorporated into such material.

\section{References}

Armsworth, M.W. (1990). A qualitative analysis of adult incest survivors' responses to sexual involvement with therapists. Child Abuse and Neglect, 14, 541-554.

Barlow, D.H. (2010). Negative effects from psychological treatments: A perspective. American Psychologist, 65, 13-20.

Bates, C. M. and Brodsky, A. M. (1989) Sex in the Therapy Hour: A Case of Professional Incest. New York: Guilford Press.

Bates, Y. (ed.) (2006) Shouldn't I be Feeling Better by Now? Client Views of Therapy. London: Palgrave.

Bergin, A.E. (1963). The effects of psychotherapy: Negative results revisited. Journal of Counseling Psychology, 10, 244-250.

Binder, J.L., \& Strupp, H.H. (1997). 'Negative process': A recurrently discovered and underestimated facet of therapeutic process and outcome in the individual psychotherapy of adults. Clinical Psychology: Science and Practice, 4, 121139.

Castonguay, L.G., Boswell, J.F., Constantino, M.J., Goldfried, M.R., \& Hill, C.E. (2010). Training implications of harmful effects of psychological treatments. American Psychologist, 65, 34-49. 
Dale, P., Allen, J. \& Measor, L. (1998). Counselling adults who were abused as children: Clients' perceptions of efficacy, client-counsellor communication, and dissatisfaction. British Journal of Guidance and Counselling, 26, 141-157.

Dimidjian, S., \& Hollon, S.D. (2010). How would we know if psychotherapy were harmful? American Psychologist, 65, 21-33.

Elliott, R., Fischer, C. T., \& Rennie, D. L. (1999). Evolving guidelines for publication of qualitative research studies in psychology and related fields. British Journal of Clinical Psychology, 38, 221-229.

Frenken, J., \& van Stolk. B. (1990). Incest victim: inadequate help by professionals. Child Abuse and Neglect, 14, 253-263.

Grunebaum, H. (1986). Harmful psychotherapy experiences. American Journal of Psychotherapy, 40, 165-177.

Hatfield, D., McCullough, L., Frantz, S.H.B., \& Krieger, K. (2010). Do we know when our clients get worse? An investigation of therapists' ability to detect negative client change. Clinical Psychology and Psychotherapy, 17, 25-32. DOI: $10.1002 / \mathrm{cpp} .656$

Henkelman, J. \& Paulson, B. L. (2006). The client as the expert: Researching hindering experiences in counselling. Counselling Psychology Quarterly, 19, 139-150.

Khele, S., Symons, C. and Wheeler, S. (2008). An analysis of complaints to the British Association for Counselling and Psychotherapy, 1996-2006. Counselling and Psychotherapy Research, 8, 124-132. 
Kraus, D. R., Castonguay, L., Boswell, J. F., Nordberg, S. S. and Hayes, J. A. (2011). Therapist effectiveness: Implications for accountability and patient care. Psychotherapy Research, 21, 267 - 276.

Levitt, H. (2002). Voicing the unvoiced: Narrative formulation and silences. Journal of Counseling Psychology Quarterly, 15, 333-350.

Lietaer, G. (1992). Helping and hindering processes in client-centred/experiential psychotherapy: A content analysis of client counsellor postsession perceptions: In S. G. Toukmanian and D. L. Rennie (Eds.). Psychotherapy process research: Paradigmatic and narrative approaches. (pp. 134-162). Thousand Oaks, CA: Sage.

Lilienfeld , S.O. (2007). Psychological treatments that cause harm. Perspectives on Psychological Science, 2, 53-70. DOI: 10.1111/j.1745-6916.2007.00029.x

Nilsson, T., Svensson, M., Sandell, R., \& Clinton, D. (2007). Patients' experiences of change in cognitive-behavioral therapy and psychodynamic therapy: A qualitative comparative study. Psychotherapy Research, 17, 553-566.

Okiishi, J., Lambert, M.J., Nielsen, S.L. and Ogles, B.M. (2003). Waiting for supershrink: an empirical analysis of therapist effects. Clinical Psychology and Psychotherapy, 10, 361-373.

Paulson, B. L., Everall, R. D. \& Stuart, J. (2001). Client perceptions of hindering experiences in counselling. Counselling and Psychotherapy Research, 1:1, 5361.

Sells, S. P., Smith, T.E. \& Moon, S. (1996). An ethnographic study of client and counselor perceptions of psychotherapy effectiveness in a university-based training clinic. Journal of Marital and Family Psychotherapy, 22, 321 - 342. 
Smith, J. A., Flowers, P. \& Larkin, M. (2009). Interpretative Phenomenological Analysis: theory, method and research. London: Sage.

Stewart, R.E. \& Chambless, D.L. (2008). Treatment failures in private practice: How do psychologists proceed? Professional Psychology: Research and Practice, 39, 176-181. DOI: 10.1037/0735-7028.39.2.176

Symons, C. (2012) Complaints and Complaining in Counselling and Psychotherapy: Organisational and Client Perspectives. Unpublished PhD thesis, Institute for Lifelong Learning, University of Leicester.

Symons, C., Khele, S., Rogers, J., Turner, J. and Wheeler, S. (2011) Allegations of serious professional misconduct: An analysis of the British Association for Counselling and Psychotherapy's Article 4.6 cases, 1998-2007. Counselling and Psychotherapy Research, 11, 257-265.

von Below, C. \& Werbart, A. (2012). Dissatisfied psychotherapy patients: A tentative conceptual model grounded in the participant's view. Psychoanalytic Psychotherapy, 26, 211-229. 
Table 1. Thematic analysis of the experience of receiving bad therapy

Sourcing a therapist (10 participants)

The therapist working to their own agenda (10)

- $\quad$ This is how its going to be (8)

- You are not important to me: an absence of genuine interest and caring (9)

- $\quad$ Therapist not listening (9)

- $\quad$ Therapist not collaborating (9)

- $\quad$ Hoping it would get better (7)

- $\quad$ Impact of therapist presence (9)

- $\quad$ Hanging on in therapy (8)

Pivotal moments - deciding not to continue (10)

- I didn't feel met (10)

- $\quad$ Shell shocked (8)

- $\quad$ Feeling afraid/uncomfortable (9)

- $\quad$ Feeling used (8)

Impact on the participant after receiving unhelpful therapy (10)

- $\quad$ It left a bad taste (10)

- $\quad$ Visceral hangover (10) 
- $\quad$ Feeling cheated (10)

- I left something of myself in the counselling room (10)

- $\quad$ Long-term learning (10)

- $\quad$ The experience of complaining (1) 